\title{
sciendo
}

\section{Applying the Input-Process-Outcome Model to Team Learning in Sport Sciences: An Exploratory Qualitative Study on Twenty Soccer Players}

\author{
by \\ Thibault Kérivel ${ }^{1,2}$, Cyril Bossard², Gilles Kermarrec ${ }^{2}$
}

In sport science literature, referring to the Input-Process-Outcome (IPO) model, few studies demonstrated links between team training and team learning despites several calls for empirical studies. Thus, this study aimed at exploring systemically the building process of the interpersonal coordination by focusing on (1) a specific antecedent (i.e., video feedback during practice), (2) the influence of this antecedent on the team learning process, and (3) outcomes from this process as shared cognitive contents. Thus, this study was original by examining empirically the IPO model in a sport-training context. Our study showed that Input influenced the specific learning Process during practice (five processes) and video feedback sessions (five processes) and produced Outcomes (six typical shared cognitive contents). Finally, results are discussed in relation to team learning processes theoretically identified in the literature and an IPO soccer model adapted to team learning in a soccer context is proposed.

Key words: team learning, team training, soccer, video feedback.

\section{Introduction}

The social-cognitive and the ecological dynamics approaches are two well-known theoretical perspectives describing interpersonal coordination in team sports (Araujo and Bourbousson, 2016). These theoretical perspectives led to specific pedagogical models, i.e., Teaching Games for Understanding (TGfU) and Constraints-Led Approach (CLA) aiming at answering practical questions as: how to train interpersonal coordination in team sports? How to improve tactical decision making in team sports? Which pedagogical constraints lead to adaptation and learning? What kind of feedback can help players? (Kermarrec and Roure, 2016; Renshaw et al., 2016). Similarities exist between these pedagogical models: in opposition with traditional analytic training approaches, they

emphasize the importance of representative tasks such as small-sided games (SSG) in soccer (e.g., Davids et al., 2013). Nevertheless, there are major differences in theoretical principles used to guide pedagogical practice and strategies (Renshaw et al., 2016), so that teachers and coaches should make different choices when they intervene and deliver instructions or feedback (Batista et al., 2019), with hypothetical consequences on the learning process (Kermarrec and Roure, 2016; Price et al., 2019). Nevertheless, both the CLA and TGFU focused on the relationship between training strategies and learning outcomes such as team behaviors (Travassos and al., 2014), team efficacy and team members' knowledge (Stolz and Pill, 2014), so that the learning process has been neglected. There has been a shift in research focus

\footnotetext{
1 - University of Nantes, "Movement, Interactions, Performance" Lab. UFR STAPS, 25Bis Boulevard Guy Mollet, 44322 Nantes (FRANCE).

2 - University of West Brittany, Research Center for Education Learning and Didactics, 20 avenue Victor Le Gorgeu, 29200 Brest (FRANCE).
} 
from the 'process/product' paradigm to the question about how learners individually construct their knowledge in relation to their learning environment (Tan et al., 2012). Thus, this study aimed at exploring the learning process and shared cognitive outcomes emerging while players were practicing a soccer SSG and were guided through immediate video feedback.

Learning processes as a critical consequence of team training strategies

Team learning processes represent the building process of interpersonal coordination during a team training session (Decuyper et al., 2010). According to McEwan and Beauchamp (2014), studying team learning processes should be critical for a better understanding of team training. The theoretical Input-Process-Outcome model (IPO) was recently considered as relevant to investigate relationships between team training $(\mathrm{I})$, team learning $(\mathrm{P})$ and team coordination $(\mathrm{O})$ (Decuyper et al., 2010; McEwan and Beauchamp, 2014). Input is defined as the set of elements in the environment that could have an influence on the learning process and its outcome. Although previous research has not considered the importance of the process by studying only the relationship between the input and outcomes or output (Salas et al., 2008, 2014), IPO research should try to put in light the role of team learning processes (Edmondson et al., 2007). Considering the IPO model as a holistic system, Decuyper et al. (2010) suggested that seven team-learning processes could be distinguished within the IPO system (Table 1).

More recently, the IPO model has been theoretically adapted from ergonomics to sport sciences (McEwan and Beauchamp, 2014). Based on this model, team learning processes are described to better understand the construction of interpersonal coordination in a team sports setting (Table 2).

Mc Ewan's (2014) model tried to preserve the dynamics of the IPO system. It promoted four stages / phases (i.e., preparation, execution, evaluation, adjustment) which could contribute to a better analysis of a team training session. Those two models (Decuyper et al., 2010; McEwan and Beauchamp, 2014) help fully understand the importance of the team learning process within the IPO model. Nevertheless, despite these theoretical advances, there is a lack of empirical investigations considering Input, Process and Outcome in a team sport-training context.

Feedback as a critical tool within team training strategies

Among the elements identified as input within training strategies, the use of instructions and feedback (i.e. moment of instructions and feedback, type of instructions and feedback, content of instructions and feedback) has recently been questioned (Batista et al., 2019; Price et al., 2019). Teaching Games for Understanding is one of the most recognized team training models, aiming at developing teammates knowledge about their role, co-constructing a common goal, and achieving relevant tactical behaviour (Gréhaigne et al., 2001; Griffin and Butler, 2005). In the TGfU perspective, feedback is delivered through questioning and debates of ideas, and explicit learning processes are favoured (Kermarrec and Roure, 2016 ; Raab, 2007). Literature reviews showed that those training approaches favoured knowledge construction, but findings are non-consistent when researchers investigated players' efficacy or team performance outcomes (Gréhaigne and Nadeau, 2015; Kermarrec and Roure, 2016; Raab, 2007; Stolz and Pill, 2014). Moreover, numerous recent studies have demonstrated that video feedback combined with questioning improves decisionmaking in tennis (Garcia-Gonzales et al., 2014) and athletes' tactical knowledge in volleyball (GilArias et al., 2015) as well as in tennis (Moreno et al., 2016).

Taking into account those advances and limitations, an innovative team training strategy recently emerged as "meaningful experience pedagogy" (Kermarrec and Bossard, 2017). The Meaningful Experience Pedagogy (MEP), in comparison with traditional analytic training approaches, urges the use of small-sided games (SSG) in soccer (Kermarrec and Roure, 2016). Based on a naturalistic ergonomic approach (TNDM Approach, Klein et al., 2008), MEP is a blend of practice and video feedback (Kermarrec and Bossard, 2017): practice should lead to compiling extensive experiences, while video feedback should lead to reviewing significant experiences. Moreover, coaches' interventions consist in delivering short video feedback focusing players' attention on each other's positions and functional relationships between 
teammates. Theoretically, video feedback should be useful for coaches and teachers to sustain analogic learning processes and to highlight successful configuration of play. Nevertheless, very few empirical studies have been conducted to investigate learning processes and outcomes in MEP training sessions. Thus, based on the IPO model's hypothesis, this study aimed at exploring the building process of the interpersonal coordination of soccer players based on MEP, by focusing on (1) a specific antecedent (i.e., video feedback), (2) the influence of this antecedent on the team learning process, and (3) resulting outcomes as shared cognitive contents.

\section{Methods}

\section{Participants}

Twenty students participated in this study. All of them were enrolled in a soccer course within the third year of a sport sciences post-graduate curriculum at a French university. Players ranged in age from 20 to 23 years and they had been playing soccer in the French Soccer Federation championships for 10 to 14 years; their performance level was from regional to national. The aim of the study was briefly explained to each participant and they all signed a consent form. Two experienced teachers designed the training protocol; both of them were certified in sport sciences and in soccer coaching.

\section{Procedures}

The soccer course was a twenty-four week course during the third year of sport sciences curriculum. During the first course unit, two teachers composed two teams with equal competencies. One teacher was in charge of the second-year soccer course and the second teacher supervised the third-year soccer course. Players' individual skills had been assessed during the second-year soccer course. More specifically, individual technical and tactical skills were evaluated during an offensive stage in small-sided games, and a test score was delivered to each student at the end of the second-year course. Based on this dataset, the two teachers were able to compose two teams of equal competencies. The aim of the course was to improve the collective performance of each team (Figure 1). The study was conducted during the sixth (i.e., training coordination) and the seventh course unit (i.e., assessing coordination).

\section{A representative SSG in soccer}

The training task was a small-sided game (SSG). Since a team as a complex system requires coordination for success, small-sided games are considered a representative task device for team training (Davids et al., 2013; Stolz and Pill, 2014). The practice is 9 vs. 9 in a small-sided field that is divided into seven areas as shown in Figure 2. Consequently, each player within a team was positioned in a specific area according to their role. Moreover, two joker players in flank areas could help the team in possession of the ball. The goal for each team was to reach one of the two targets. The offensive team had to pass over the defensive lines into the next space for a teammate using only the one touch pass. Only one defender player from each defensive area could leave his own space and try to recover the ball in the attackers' space. Thus, when a team got the possession of the ball, offensive players had to pass the ball successively through one or two lines of defenders. The task's objective was presented to all participants: they had to improve the ball's progression between each line (defender to midfield, midfield to forward).

After a warm-up, the training session lasted 60 min within the sixth unit course. Players practiced the task for $20 \mathrm{~min}$ without any feedback: this was considered to be the pre-test for the study. The main training period lasted approximately $40 \mathrm{~min}$ with specific teacher' interventions and feedback. The evaluation session in the task lasted $20 \mathrm{~min}$ within the seventh unit and was considered to be the posttest.

\section{Team training strategy}

The training session was based on the MEP principles. First, team training needs a lot of time to practice. Second, the teacher had to organize three short interruptions of the game to deliver video feedback. Video tools included a wide-angle camera set at $4 \mathrm{~m}$ height. This camera was linked to a touch pad by a Wi-Fi signal. The teacher could stop the game, gather players around the touchpad, let them review their last trial, and encourage them to play again. The teacher could also highlight a configuration of a play through frozen images. He could indicate successful configuration of play. Two researchers supervised the intervention to reduce the gap between the planned training procedure and the 
real procedure.

\section{Data collection}

Verbal data were collected during individual post-training interviews (Macquet and Stanton, 2014), also called self-confrontation interviews (Macquet, 2013) or video-cued interviews (Kermarrec and Bossard, 2014). The interviews were conducted as soon as possible after the evaluation session (i.e., within 48 or 72 h). The interview focused on the feedback delivery phases (from 1 to $5 \mathrm{~min}$ each) and on the three game phases (approximately $7 \mathrm{~min}$ each) following teacher' feedback interruptions. The interviewer used specific questions to encourage the participant to comment on his/her own experiences during the training session (i.e., What did you aim to do? What were you thinking about? What were you looking at?). The participant could stop the video as he/she wanted and take more time to describe a specific event or a meaningful moment. The interview took place immediately after the training session or some days after, depending on the availability of participants. Finally, 18 interviews were conducted and recorded (we did not meet players who played as jokers). They lasted between 30 and $45 \mathrm{~min}$. From this material, we prepared a table for each players' activity.

\section{Data processing}

Each player's verbal report about the training session was processed separately. Firstly, the first researcher divided the transcripts into meaningful units according to the hypothetical aspects of the team training system (i.e., the IPO model). Thus, we especially focused on team learning processes during feedback delivery (e.g. "I can visualize the game situation..."; "We are sharing solutions..."), players' learning processes while practicing the task (e.g., "I'm talking to him to guide his play; I'm focusing on my partner's run..."), and the emerging cognitive outcomes (e.g., "I think we should better go to the ball side..."; "I know we should move more and more..."). Some affective outcomes (e.g., "I don't feel confident enough") were rarely elicited in this case study so that they were not pursued for further analysis. There were135 units related to team learning processes during feedback delivery; 431 units related to team learning processes while practicing the task; and 306 units described cognitive outcomes mobilized by participants. Secondly, researchers examined part of the selected units step by step depending on their meaning. For this data analysis step, as in Macquet's (2013) and Kermarrec and Bossard's (2014) method, an inductive content analysis (Strauss and Corbin, 1998) was carried out. Team learning processes during feedback delivery were divided into seven empirical categories. Team learning processes while practicing the task were divided into five empirical categories. Cognitive outcomes were divided into six empirical categories. Thirdly, to ensure the validity of data analysis, three researchers were involved in data processing. The second researcher reviewed the meaningful units' selection, and the inductive content analysis. The third researcher helped in case of disagreement between the first and the second researcher. They discussed until a consensus was reached. The reliability of the coding procedure was finally assessed with the Cohen's (1960) Kappa test. The agreement rate was $92.28 \%, \boldsymbol{\kappa}=.88$, with a confidence interval of 0.85 to 0.95 for the behavioural processes' categories. The agreement rate was $90.40 \%, \boldsymbol{\kappa}=$. 88 , with a confidence interval of 0.84 to 0.92 for the cognitive outcomes' categories.

\section{Results}

This section describes the team learning processes which players used during feedback delivery. Then, we focused on their practice experiences and their use of team learning processes while they went back to the training task. Finally, content of cognitive outcomes from the group of participants is presented.

Team Learning Processes during feedback delivery

Analysis and comparison of the players' meaningful units related to feedback delivery revealed five team learning processes. The following table is the presentation of five teamlearning processes during VFB delivery.

Players' experiences in a training session were influenced by feedback delivered of a teacher. Video feedback led players to specific team learning processes. Mainly, VFB helped them visualize their mistakes, previous situations or problems in the game, such as the opposite team organisation. Thanks to these "pictures" they were able to share, understand, plan, and validate solutions they had experienced during the practice phase. 
Table 1

Seven processes in the Team Learning activity (Decuyper et al., 2010)

\begin{tabular}{|c|c|}
\hline Process & Definition \\
\hline Sharing & $\begin{array}{l}\text { Sharing is the process of communicating knowledge, competencies, opinions or creative thoughts } \\
\text { of one team member to other team members, who were not previously aware that these were } \\
\text { present in the team. }\end{array}$ \\
\hline Co-Construction & $\begin{array}{l}\text { Co-construction is the mutual process of developing shared knowledge and building shared } \\
\text { meaning by refining, building on or modifying an original offer in some way }\end{array}$ \\
\hline Constructive conflict & $\begin{array}{l}\text { Constructive conflict is a process of negotiation or dialogue that uncovers diversity in identity, } \\
\text { opinion, etc. within the team. }\end{array}$ \\
\hline Team reflexivity & $\begin{array}{l}\text { team reflexivity is defined as the processes of co-constructing, de-constructing and re- } \\
\text { constructing shared mental models about current reality, and about team goals and methods. }\end{array}$ \\
\hline Team activity & $\begin{array}{l}\text { Team activity is the process of team members working together, mobilizing physical and } \\
\text { psychological means required for goal attainment. }\end{array}$ \\
\hline Boundary crossing & $\begin{array}{l}\text { Boundary crossing is the process that describes the communicative processes of learning across } \\
\text { borders between the team and its environment or between team members that represent different } \\
\text { groups, such as other group learning }\end{array}$ \\
\hline Storage and retrieval & $\begin{array}{l}\text { Storage and retrieval are defined as a process that allows to store shared knowledge, procedures, } \\
\text { shared ideas, plans, and habits from other collective learning processes, and make it clear that this } \\
\text { information remains available for retrieve in due course. }\end{array}$ \\
\hline
\end{tabular}

Table 2

Theoretical description of team learning processes in sport (McEwan and Beauchamp, 2014) Step Process Definition

Mission analysis involves team members collectively defining and evaluating the team's purpose, including the identification of its main tasks, the operative environmental conditions, team abilities, time constraints, and resources available for carrying out the mission

Prior to the task

Mission analysis execution Goal specification involves the identification of the level of performance
that team members must attain in order to fulfill the team's mission Planning involves the formulation of the process goals that put members

Planning on a specified path toward mission accomplishment

Execution
putting into action
what was planned
in the preparation
phase

Coordination Coordination involves managing the sequence and timing of team

members' interdependent actions

putting into action what was planned phase

Cooperation
Communication
task execution while in pursuit of the team's common purpose Communication, which has also been referred to as information
exchange or information sharing, is the extent to which team members share task-related information with each other

\begin{tabular}{|c|c|c|}
\hline \multicolumn{3}{|l|}{ Evaluation } \\
\hline \multirow{2}{*}{$\begin{array}{l}\text { Questioning about } \\
\text { if they are on the } \\
\text { correct path } \\
\text { toward fulfilling } \\
\text { their purposes }\end{array}$} & Performance monitoring & $\begin{array}{l}\text { Performance monitoring involves tracking progress toward team goal } \\
\text { attainment and consequently determining what still needs to be done }\end{array}$ \\
\hline & System monitoring & $\begin{array}{l}\text { System monitoring involves tracking both the internal and external } \\
\text { environmental conditions related to the task accomplishment }\end{array}$ \\
\hline \multirow{4}{*}{$\begin{array}{c}\frac{\text { Adjustment }}{\text { Follow-up }} \\
\text { evaluation to } \\
\text { reach their goals }\end{array}$} & Problem solving & $\begin{array}{l}\text { Problem solving is a process whereby members collaboratively } \\
\text { brainstorm and implement a solution that brings their current conditions } \\
\text { closer to the desired outcomes }\end{array}$ \\
\hline & Backing up & $\begin{array}{l}\text { Backing-up process consists of helping another teammate perform } \\
\text { his/her individual roles }\end{array}$ \\
\hline & Intra-team coaching & $\begin{array}{l}\text { Intra-team coaching refers to team members providing verbal } \\
\text { constructive feedback to each other regarding task performance }\end{array}$ \\
\hline & Innovation & $\begin{array}{l}\text { Innovation is a process whereby teams introduce novel approaches to the } \\
\text { task execution in order to maintain or improve performance }\end{array}$ \\
\hline
\end{tabular}


Table 3

Presentation of five team-learning processes during feedback delivery

\begin{tabular}{|c|c|c|c|}
\hline \multicolumn{4}{|c|}{ Team learning processes during feedback delivery } \\
\hline Examples of meaningful units & Empirical categorization & F. MU (\%) & N. Part. \\
\hline "There we see the line of three players" & $\begin{array}{l}\text { Visualizing (game situation, opposite } \\
\text { team organization, mistakes) }\end{array}$ & $81(0.60)$ & 16 \\
\hline $\begin{array}{l}\text { "What we just said / showed will serve me } \\
\text { in the game" }\end{array}$ & Planning future actions & $20(0.15)$ & 10 \\
\hline "I'm listening, now it makes sense" & Teacher's instructions sense-making & $17(0.13)$ & 11 \\
\hline "Chatting / seeing validates my ideas" & Validating solutions & $10(0.07)$ & 6 \\
\hline "We are sharing solutions" & Sharing solutions & $7(0.05)$ & 4 \\
\hline Total of Meaningful Units & & 135 & \\
\hline
\end{tabular}

Note: $F$. US = Frequency of meaningful units $(\%), N$. Part. = Number of participants concerned within a training condition.

Table 4

Team learning processes during the task practice

\begin{tabular}{|c|c|c|c|}
\hline \multicolumn{4}{|l|}{ Team Learning Processes during the task practice } \\
\hline Examples of meaningful units & Empirical categorization & F. MU $(\%)$ & N. Part. \\
\hline "Here, we talk together, it helps" & Communicating between teammates & $21(0.05)$ & 13 \\
\hline $\begin{array}{l}\text { "I can see my partner's run, he incites me to try the } \\
\text { pass" }\end{array}$ & $\begin{array}{l}\text { Perceiving and adapting to } \\
\text { teammates' behaviours }\end{array}$ & $238(0.55)$ & 18 \\
\hline "Here, I feel that it goes well, it's smoother" & $\begin{array}{l}\text { Assessing and validating a collective } \\
\text { behaviour }\end{array}$ & $38(0.09)$ & 12 \\
\hline $\begin{array}{l}\text { "To be blocked in areas, it reminds me of the player's } \\
\text { position in a competition match" }\end{array}$ & Feeling task constraints & $86(0.20)$ & 16 \\
\hline $\begin{array}{l}\text { "I'm thinking that I'm slow; I should have played more } \\
\text { quickly" }\end{array}$ & $\begin{array}{l}\text { Assessing individuals' own } \\
\text { difficulties within the task }\end{array}$ & $48(0.11)$ & 16 \\
\hline Total processes & & $\begin{array}{l}431 \\
(1)\end{array}$ & \\
\hline
\end{tabular}

Note: F. US = Frequency of meaningful units (\%), N. Part. = Number of participants concerned within a training condition.

Table 5

Cognitive outcomes emerging during the training session

\begin{tabular}{|c|c|c|c|c|}
\hline \multicolumn{5}{|l|}{ Cognitive Outcomes } \\
\hline Examples of meaningful units & Empirical categorization & $\begin{array}{l}\text { Theoretical } \\
\text { categorization }\end{array}$ & F. MU (\%) & N. Part. \\
\hline "We had to try to reach the next space" & $\begin{array}{l}\text { To play towards the front over } \\
\text { defensive lines }\end{array}$ & Goal & $62(0.20)$ & 16 \\
\hline "I try to move forward" & To just move & & $21(0.05)$ & 12 \\
\hline $\begin{array}{l}\text { "Here, I go into the gap between the two } \\
\text { opponents" }\end{array}$ & To move to a gap & & $43(0.14)$ & 17 \\
\hline $\begin{array}{l}\text { "I offer a solution close to my teammate in } \\
\text { possession of the ball" }\end{array}$ & To go away from or toward the ball & Knowledge & $67(0.22)$ & 15 \\
\hline "I try to keep high rhythm on my pass" & To gain speed or time & & $59(0.19)$ & 14 \\
\hline "I try to make them move" & To provoke opponents' moves & & $53(0.17)$ & 15 \\
\hline Total Knowledge & & & $244(0.80)$ & \\
\hline Total Cognitive Outcomes & & & $\begin{array}{l}306 \\
(1)\end{array}$ & \\
\hline
\end{tabular}

Note: F. US = Frequency of meaningful units (\%), N. Part. = Number of participants concerned within a training condition. 


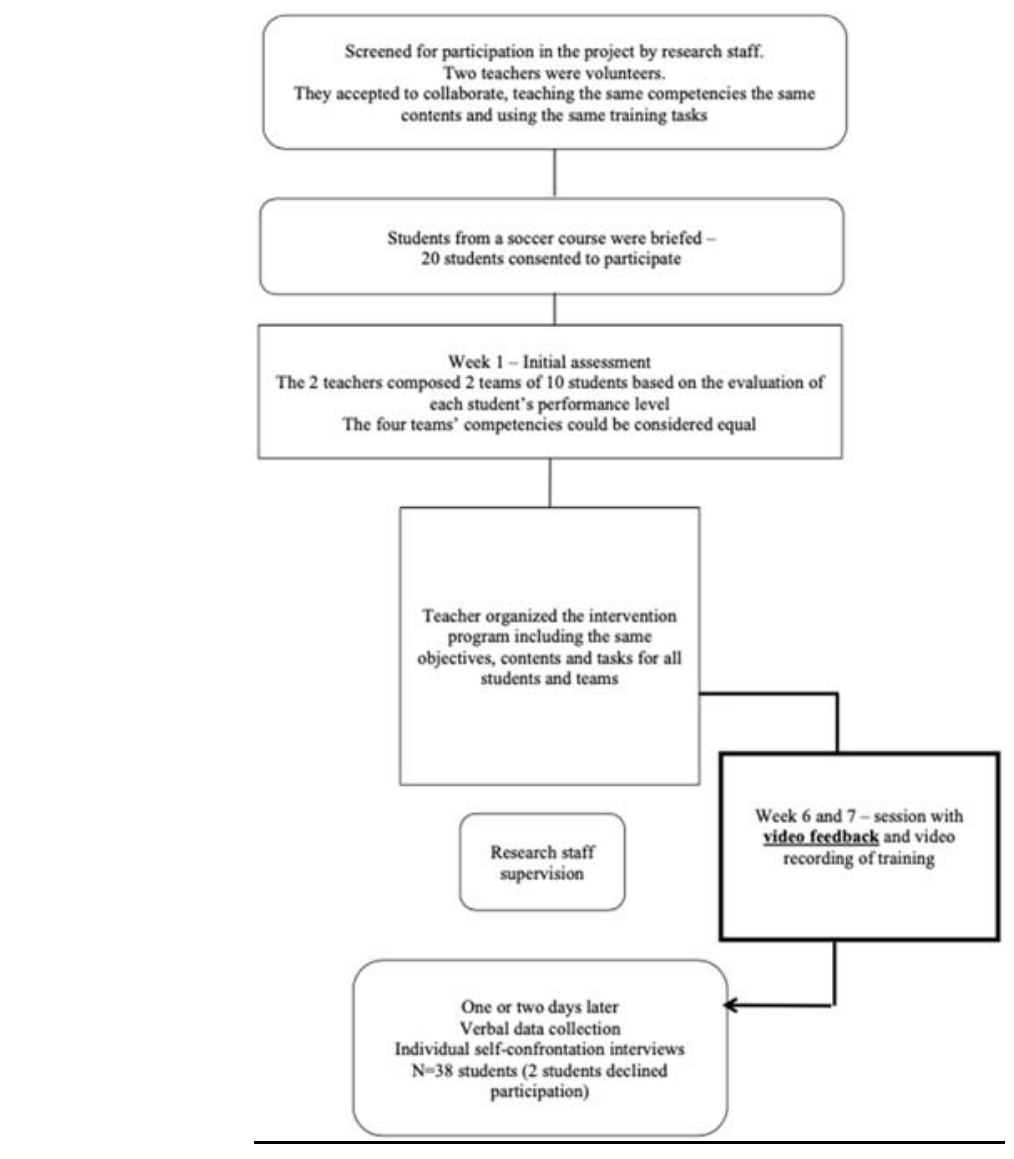

Figure 1

The procedure's description

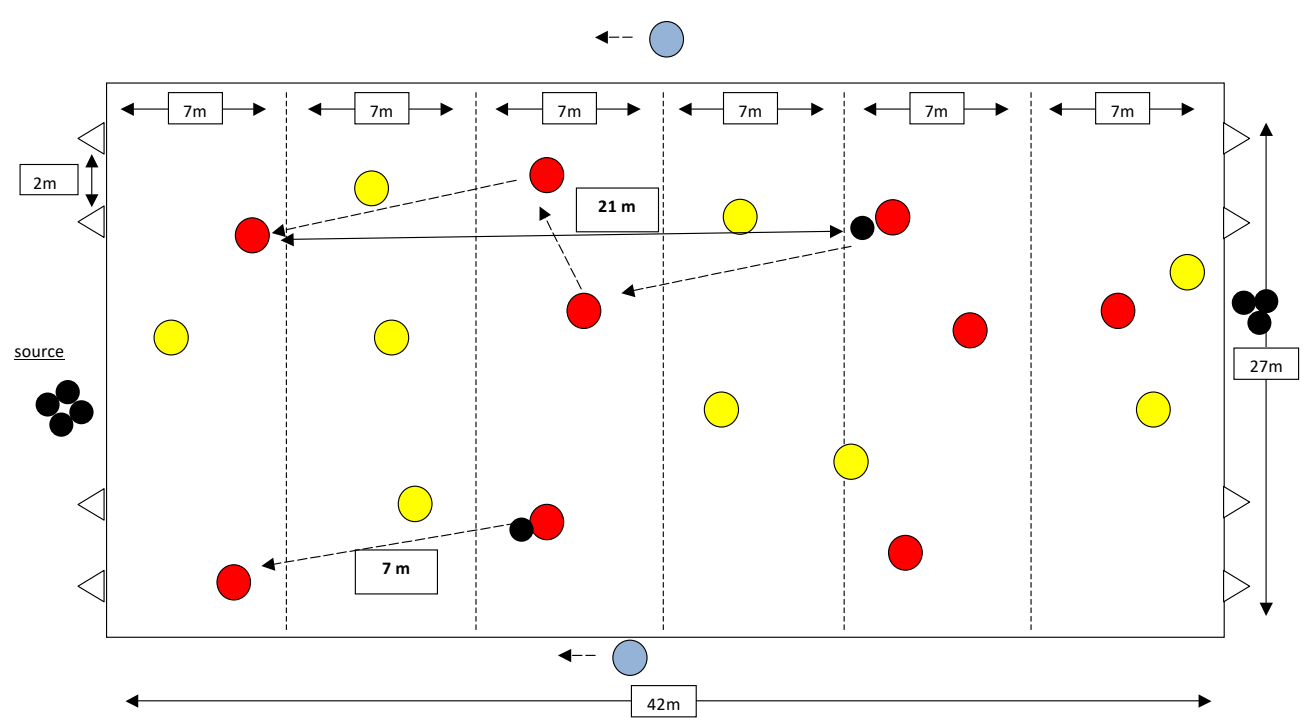

Figure 2

The Baby-foot, a Small-Sided Game 


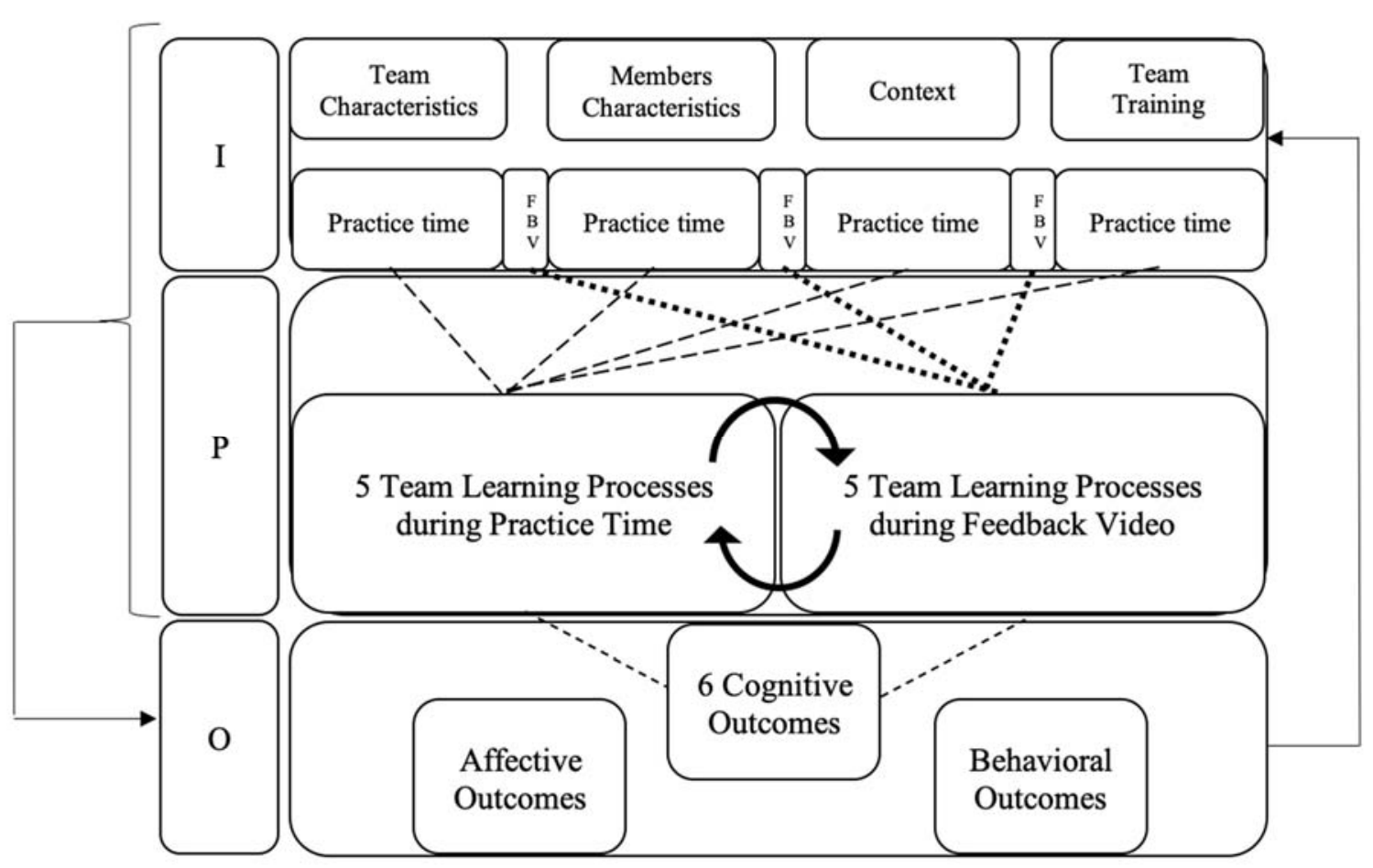

Figure 3

IPO Model adapted to team learning in a soccer context

Learning processes the players used to improve coordination during practice

Analysis of the players' meaningful units related to task practice revealed five types of learning processes. Table 4 presents the team learning processes gives an example of each of them and shows to what extent they were elicited and shared.

Reviewing carefully the content of each category, researchers identified five types of learning processes when players had benefited from VFB. They went back to the game with some "pictures in the head". Those pictures should help them to communicate, perceive and adapt to teammates, and to valid collective behaviour they have previously shared, validated and planned during the feedback. Furthermore, the initial practice phase led them to identify their own difficulties, and to feel task constraints. That's why feedback could have been helpful to visualise the problem and then to build shared solutions. Content of cognitive outcomes

The analysis of the content of meaningful units related to cognitive outcomes led to six empirical categories: they are detailed in Table 5 .

Examining carefully the content of each cognitive outcome category, researchers classified them into more general categories, related to Team Cognition advances. To play towards the front over defensive lines referred to the goal of the game, and the other categories referred to different means or knowledge the players built and shared to reach the goal (Table 3). Furthermore, frequencies of cognitive outcome categories (from 11 to $29 \%$ ) and the number of players (from 12 to 17 inside a training group) 
included in each category highlighted how much the different contents were shared.

\section{Discussion}

The aim of our study was to explore the relationships between video feedback, team learning processes and shared cognitive contents, as an empirical investigation of the IPO model perspective. To this end, we investigated coordination building within teams during a soccer SSG. Our results highlighted 10 learning processes which were specific to the video feedback stage or to the practice stage. Most of these learning processes were shared between more than 10 players from our participants. Players mainly used the visualizing process during video feedback delivery ( $60 \%$ of the $\mathrm{MU})$, and perceiving and adapting to teammates' behaviors when practicing the SSG $(55 \%$ of the MU). Our results can be discussed in two points: (1) highlighting the team-learning processes empirically identified; (2) the emergence of shared cognitive contents.

Team-learning processes: from theory towards empirical insights

Previously, researchers presented teamlearning processes in IPO from a theoretical perspective (Decuyper et al., 2010; McEwan and Beauchamp, 2014). We explored this topic within an empirical and naturalistic approach. Thus, from our empirical results the following sections aim to show main similarities and differences with previous theoretical modeling. The learning processes identified in our setting are discussed in 4 temporal stages, in accordance with the dynamics of the training - learning process.

Feeling the problem: practicing the game

First, our study showed that players mobilized processes oriented toward feeling task constraints ( $20 \%$ of the MU) and tried to assess individuals' difficulties within the task $(11 \%)$. These learning processes could be categorized as processes theoretically identified as "mission analysis" or "system monitoring" in McEwan and Beauchamp (2014) proposals. Furthermore, our study showed that players focused on space perception and the opposite team organization to feel the problem. Paying attention to another team's organization was identified as a cross boundary process in Decuyper et al. (2010). Theoretically, this process should help identify problems, promote collective innovation and transfer activity between the training situation and the performance situation. In accordance with MEP, practice should help players better understand a training situation (Kermarrec and Bossard, 2017).

Visualizing the problem: video feedback

In our study, video feedback favored visualization processes. This visualization process is not far from the process of collective reflexivity. According to Decuyper et al. (2010) collective reflexivity is the development of a "clear vision" of the current state of the collective (e.g. the team), of the state desired by the collective and of how they will reach that state. This process helps keep the team in the "right direction" during team learning activity and promotes collective adaptation. According to McEwan and Beauchamp (2014) visualization sharing allows players to plan future actions. Our results also suggest that video feedback is a relevant tool to help the player to construct a shared picture of a collective action. It could be hypothesized that such a shared picture could help athletes improve their decision-making (Garcia-Gonzales et al., 2014; Kermarrec and Plassart, 2017).

Team adaptation: practicing the game

The team behavior adaptation emerged when players went back to the game and made effort to perceive and adapt their behavior to teammates' behaviors (55\%), to assess and validate a collective behavior (9\%), to communicate between themselves (5\%). These different Team Learning Processes refer to the process of collective activity and should contribute to the storage and retrieval process identified by Decuyper et al. (2010). When team members work together for a common purpose, they try to increase the quality of interpersonal coordination. In the execution stage according to McEwan and Beauchamp (2014), team adaptation is sustained by communication, cooperation and coordination. These results demonstrated that team behavior adaptation needed different learning processes. Previous team sport training frameworks did not consider such a variety of processes. In the ecological dynamics approach behavior adaptation is viewed as perceptionaction coupling and an implicit learning process (Davids et al., 2013), while in the Teaching Games for Understanding approach team adaptation is 
focused on explicit learning (i.e., assessment and verbal communication). In accordance with the MEP approach, this study underlines the interest of a large range of learning processes and highlights the importance of mutual adaptation between teammates.

Understanding, planning, sharing and validating a solution: video feedback

Thus, our data highlighted that video feedback also helped learners to understand $(13 \%)$, plan $(15 \%)$, share $(5 \%)$ and validate solutions $(7 \%)$, which is in accordance with coconstruction (Decuyper et al., 2010). Coconstruction is a process of interaction between team members that promotes the shared construction of meaningful elements. Furthermore, during feedback delivery, players activated assessment processes. The assessment process in our study can be assimilated to team performance evaluation processes (performance and system monitoring) highlighted by McEwan and Beauchamp (2014). These processes allow players to control the advancement in the problem solving process and to assess their own performance. During the co-construction stages we highlighted that students shared solutions and constructed consensual knowledge to perform the game. This co-construction process reminds processes such as problem solving, backing up and intra-team coaching, identified in the adjustment stage (McEwan and Beauchamp, 2014). These processes supported by video feedback could explain why video feedback improves knowledge sophistication, structuration and accuracy in team sports (Gil-Arias et al., 2015; Moreno et al., 2016).

Shared cognitive contents emerged from practice and video feedback

Our results suggest that specific input (SSG and video feedback) supported learning and favored shared cognitive outcomes. Literature shows that there is a relationship between team training protocols and effects in terms of cognitive affective or behavioral outcomes (Davids et al., 2013; Salas et al., 2008, 2014 ; Stolz and Pill, 2014). In our study these cognitive outcomes were categorized as "shared goals" or "shared knowledge". These results are in line with other studies about team training effects on knowledge sharing (Stolz and Pill, 2014). In previous research (for a review, see Gréhaigne and Nadeau, 2015;
Stolz and Pill, 2014), knowledge was coconstructed in a training program if athletes were asked to verbalize it. In accordance with Meaningful Experiences Pedagogy (Kermarrec and Bossard, 2017), our study demonstrated that knowledge also emerged from practice, and that brief video feedback was sufficient to support knowledge building. From our study we could also highlight the role of the training design in sharing diffusion of cognitive contents inside teams: 15 of the 18 teammates shared similar goals and knowledge. Nevertheless, the context of our study (i.e., a sport sciences post-graduate curriculum) probably contributed to the similarity of the contents, while in elite teams training, sharing generally results in complementary goals knowledge. Goals in elite teams are dependent on status or positions held in sports teams (DeKeukelaere et al., 2013).

A dynamic-cyclic representation of the learning training process

In our study, we highlighted that the IPO system could work in four stages, i.e.: problem identification through practice, problem visualization through video feedback delivery, coconstructing team coordination through practice, picturing of a solution through video feedback. These stages are not so far from TGfU strategy associated steps: practice of the representative task, observation and evaluation of difficulties, analysis of the task and co-construction and verbalization of solutions, applying solutions within the task (Gréhaigne and Nadeau, 2015). Results from our study show that instead of a sequential step-by-step representation of the learning-training process, it seems that the IPO system functions as a dynamic and cyclic (allosteric) system.

Nevertheless, in our study, the process of task constraints identification and analysis is not exclusively activated off-field as McEwan and Beauchamp (2014) suggested. Players "felt the problem" during practice. In the same perspective, our study revealed that players activated assessing processes during feedback delivery and also during practice (assessing individuals' own difficulties within the task; assessing and validating a collective behavior). Thus, the findings drew attention to the fact that players assessed their performance continually during training sessions. These main differences 
between our empirical results and previous theoretical proposition could be explained by the specificity of our context. Our study tried to better understand team-learning processes in a teamsport training context, while Decuyper et al. (2010) described these processes in a work context. Furthermore, our study allows to better understand team learning processes in a soccer training context in post-graduate students, while McEwan and Beauchamp (2014) described, among other, team processes in a performanceoriented team.

\section{Conclusions}

Our explorative study aimed to better understand the team learning processes within an innovative team training approach (i.e., MEP), using video feedback. Based on a qualitative methodology, our results elicited various learning processes drawn by task practicing and the receipt of video feedback. Only few previous studies demonstrated relationships within the IPO system despite several calls for empirical studies (Decuyper et al., 2010; Hughes et al., 2016; McEwan and Beauchamp, 2014). Our study showed that Input such as video feedback influenced Processes and led to shared cognitive Outcomes. From a practical point of view, we propose to the practitioners to pay attention to the learning processes as a bridge between the task design, feedback delivery and expected outcomes. Examining the role of video feedback and other input in learning processes as well as behavioural and cognitive outcomes would be a worthwhile purpose for research in sport and other contexts.

\section{References}

Araújo D, Bourbousson J. Theoretical perspectives on interpersonal coordination for team behavior, in Interpersonal Coordination and Performance in Social Systems, eds P. Passos, K. Davids, and J. Y. Chow (London: Routledge), 2016; 126-139

Batista J, Goncalves B, Sampaio J, Castro J, Abade E, Travassos B. The influence of coaches' instruction on technical actions, tactical behaviour, and external workload in football small-sided games. Monten J Sports Sci Med, 2019; 8(1): 29-36. doi: 10.26773/mjssm.190305

Cohen J. A coefficient of agreement for nominal scales. Educ Psychol Meas, 1960; 20: 37-46

Davids K, Araújo D, Correia V, Vilar L. The science of team games: How small-sided games enhance acquisition of movement and decision-making skills. Exerc Sport Sci Rev, 2013; 41(3): 1-8

De Keukelaere C, Kermarrec G, Bossard C, Pasco D, Loor P. Forms, Contents, and Dynamics of Sharedness in an Elite Sport Team. Trav Humain, 2013; 76 (3): 227-255

Decuyper S, Dochy F, Van den Bossche P. Grasping the dynamic complexity of team learning: An integrative model for effective team learning in organizations. Educ Res Rev-neth, 2010; 5: 111-133. doi:10.1016/j.edurev.2010.02.002

Edmondson AC, Dillon JR, Roloff KS. Three perspectives on team learning. Acad Manag Ann, 2007; 1: 269314. doi:10.1080/078559811

García-González L, Moreno A, Gil A, Moreno MP, Del Villar F. Effects of Decision Training on Decision Making and Performance in Young Tennis Players. An App Res Jour of App Sp Psych, 2014; 26(4), 426440, DOI: 10.1080/10413200.2014.917441

Gil-Arias A, García-González L, Del Villar F, Moreno A, Moreno MP. Effectiveness of video feedback and interactive questioning in improving tactical knowledge in volleyball. Perc and Mot Skills, 2015; 121(3) : 635-53. doi: $10.2466 / 30$

Gréhaigne JF, Nadeau L. Teaching and learning tactics in team sports: from forgotten precursors to current perspectives. eJRIEPS, 2015; 35: 106-140

Gréhaigne JF, Godbout P, Bouthier D. The teaching and learning of decision-making in team sports. Quest, 2001; 53: 59-76

Griffin LL. Butler J. Teaching Games for Understanding: Theory, Research, and Practice. Champaign, IL: Human Kinetics; 2005

Hughes AM, Gregory ME, Joseph DL, Sonesh SC, Marlow SL, Lacerenza CN, Benishek LE, King HB, Salas, E. Saving Lives: A Meta-Analysis of Team Training in Healthcare. J Appl Psychol, 2016; 101(9): 1266304. http:// dx.doi.org/10.1037/ap10000120 
Kermarrec G. Bossard C. Intuitive and coordinated decision-making: contribution to the tactical training of football players. In F. Dosseville \& C. Garncarzyk (Eds), La prise de décision en football. PUC : Caen ; 2017

Kermarrec G. Roure C. Training and teaching decision-making in team sports games. The use of small-sided games to test theoretical models and results of research in sports science. eJRIEPS, 2016; 37 : 58-79

Kermarrec G, Bossard C. Shared Understanding and Coordination in Team Sports. Contribution of Viewpoints Changes and Shared Information Displays for Team Situation Awareness Training. In ICSport 2014-Proceedings of the 2th International Conference on Sport Sciences and Technological Supports, Rome, Italy, October 26-28, 2014

Klein C, DiazGranados D, Salas E, Le H, Burke CS, Lyons R. The effect of team building interventions on team outcomes: An update and extension. Small Gr Res, 2008; 40 (2): 181-222

Macquet AC. Getting on the same page: a method to study the consistency of coaches' and athletes' situation understanding during training sessions and competitions. The Sport Psychol, 2013; 27: 292-295

Macquet AC, Stanton NA. Do the coach and athlete have the same picture of the situation? Distributed situation awareness in an elite sport context. Appl Ergon, 2014; 45: 724-733

McEwan D, Beauchamp MR. Teamwork in sport: A theoretical and integrative review. Int Rev Sport Exer Psy, 2014; 7: 229-250

Moreno MP, Moreno A, García-González L, Hernández AUC. An intervention based on video feedback and questioning to improve tactical knowledge in expert female volleyball players, Perc. $\mathcal{E}$ Mot. Skills, 2016; 122(3): 911-32. doi: 10.1177/0031512516650628

Price A, Collins D, Stoszkowski J, Pill S. Coaching games: comparisons and contrasts. J Hum Kinet, 2018; 6(1): 126-131. doi: 10.1123/iscj.2018-0015https://doi.org/10.1123/iscj.2018-0015

Raab M. Think SMART, not hard - a review of teaching decision-making in sport from an ecological rationality perspective. Phys Educ Sport Peda, 2007; 12(1): 1-22

Renshaw I, Araújo D, Button C, Chow JI, Davids K, Moy B. Why the Constraints-led Approach is not Teaching Games for Understanding: A Clarification. Phys Educ Sport Peda, 2016; 21(5): 459-480

Salas E, Cooke NJ, Rosen MA. On teams, teamwork, and team performance: Discoveries and Developments. Hum Factors, 2008; 50(3): 540-547

Salas E, Shuffler ML, Thayer AL, Bedwell WL, Lazzara EH. Understanding and Improving Teamwork in Organizations: A Scientifically Based Practical Guide. Hum Resour Manage, 2014; 54(4): 1-25

Stolz S, Pill S. Teaching games and sport for understanding: Exploring and reconsidering its relevance in physical education. Eur Phys Educ Rev, 2014; 20(1): 36-71. DOI: 10.1177/1356336X13496001 epe.sagepub.com

Strauss A, Corbin J. Basics of Qualitative Research: Techniques and Procedures for Developing Grounded Theory. Sage: Thousand Oaks, 1998

Tan CWK, Chow JY, Davids K. How does TGfU work? Examining the relationship between learning design in TGfU and a non-linear pedagogy. Phys Educ Sport Peda, 2012; 17(4): 331-348

Travassos B, Gonçalves B, Marcelino R, Monteiro R, Sampaio J. How perceiving additional targets modifies teams' tactical behavior during football small-sided games. Hum Movement Sci, 2014 ; 38: 241-250. Doi: http://dx.doi.org/10.1016/j.humov.2014.10.005

\section{Corresponding author:}

\section{Kerivel Thibault}

University of Nantes, "Movement, Interactions, Performance" Lab. UFR STAPS,

25Bis Boulevard Guy Mollet, 44322 Nantes (FRANCE).

Phone : +33251837234 .

E-mail address: Thibault.Kerivel@gmail.com 